\title{
Performance Enhancement of Natural Convection Indirect Solar Dryer by Integrating Reflectors
}

\author{
HailayTeklu $^{1 *}$, Mulu Bayray², DawitAbay ${ }^{2}$ and Millerjothi Kalamegam ${ }^{2}$ \\ ${ }^{1}$ College of Engineering and Technology, Department of Mechanical Engineering, Adigrat \\ University, Ethiopia (*hailushtk@gmail.com). \\ ${ }^{2}$ School of Mechanical and Industrial Engineering, EiT-M, Mekelle University, Mekelle, Ethiopia.
}

\begin{abstract}
Natural convection indirect type solar dryer integrated with reflectors that can be used for drying fruits and vegetables was designed, constructed and evaluated. The study mainly tried to improve performance of a prototype natural convection indirect solar dryer. The solar dryer was integrated with reflectors and its thermal performance was experimentally analyzed and results were compared with the same dryer without reflectors. The experiments conducted included no load test to determine the stagnation temperature that can be reached and drying tests using tomato slices. During the drying test moisture content at initial and final stages were measured using moisture balance instrument. The mass of the tomato slices was measured every two hours to find the drying efficiency. Temperatures were measured using thermocouples located at the absorber plate and at the trays inside the drying cabinet. Solar radiation was also measured using pyranometer located near the dryer. During no load experiments the maximum temperature reached at the collector was around $98^{\circ} \mathrm{C}$ for the dryer without reflectors. The maximum temperature was improved to around $154^{\circ} \mathrm{C}$ during the test with reflectors. Similar temperature improvement was obtained during the drying tests as well. Due to the improvement in the temperature in the collector, the drying rate was also improved by $8 \%$ for $10 \mathrm{~kg}$ and $14 \%$ for $5 \mathrm{~kg}$ load. The experimental results indicate that the dryer performance was improved when the reflectors were added.
\end{abstract}

Keywords: Solar dryer, Collector, Reflectors, Vegetables, Moisture, Ethiopia.

\section{INTRODUCTION}

Fruits and vegetables play an essential role in human nutrition. Apart from providing flavor and variety to human diet, they serve as important sources of vitamins and minerals which will prevent diseases and promotes good health. Most fruits and vegetables contain high percentage of water and therefore are highly perishable. Therefore, preserving fruits and vegetables is necessary to keep them for a long time without further deterioration in their quality in order to utilize their nutritional value efficiently (Dikbasan, 2007).

Various methods of preservation of fruits and vegetables such as drying, controlled atmosphere, canning, dehydration, refrigeration are being used across the world. Drying is a process of moisture removal from a product. It can be achieved by various means like freeze drying, mechanical drying, vacuum drying, thermal drying and chemical drying (Hermann, 2004; Momona Ethiopian Journal of Science (MEJS), V12(2):212-222, 2020 @ CNCS, Mekelle University, ISSN:2220-184X Submitted on: $19^{\text {th }}$ November 2019 
Hawlader et al., 2006; Hawlader et al., 2005; Hailay, 2018). Solar energy is the most attractive and abundant form of renewable energy sources because it is free, environment friendly and available most of the year. The most common and simplest application of solar energy is to convert it into heat. Solar drying, as one type of solar thermal application, is the most attractive method used to preserve fruits and vegetables. It can eliminate wastage, increase the productivity of agricultural, and improve the production of fruits and vegetables in terms of quality and quantity. Studies reported in literature on solar drying attempt to improve the efficiency through optimized design and fabrication (Raju et al., 2013) or by including fan for forced circulation of air (Seveda, 2013). Design and development and prototype of a dryer were carried out previously and test results were reported in Dawit et al. (2015); and Dawit (2013).

The aim of this study was to investigate the performance improvement of an existing natural convection indirect solar dryer by incorporating reflectors. Numerical analysis was carried out to study the effect of side and bottom reflectors in enhancing the amount of radiation reaching the absorber. Based on the numerical analysis the optimum angles to position the reflectors were determined. The analysis and results have been reported in Tabet et al. (2017). Experimental tests were then carried out for both dryer without reflectors and with reflectors.

\section{MATERIALS AND METHODS}

The dryer mainly consisted of a glass cover, an absorber plate, wooden sides, bottom insulation, drying chamber and chimney. Reflectors were made by attaching solar reflective surface on a sheet metal. The reflective surface was glass film sticker having a thickness of $0.05 \mathrm{~mm}$ and $88 \%$ ofreflectivity. The cover glass was a single layer of $4 \mathrm{~mm}$ thick glass. The absorber was $1 \mathrm{~mm}$ black painted corrugated iron sheet which was enclosed in a casing made from wood in all sides and with $5 \mathrm{~cm}$ fiber glass insulation at the bottom. The drying chamber was made from wood and enclosed in casing made from sheet metal. It had three trays- top tray (Tray 1), middle tray (Tray 2) and bottom tray (Tray 3).The trays were made from perforated sheet made from plastic; it was chosen to avoid rusting and contamination of the fruits during drying.

The optimum inclination angles of the reflectors were theoretical determined to get maximum solar radiation that falls on the collector surface. The bottom reflector was kept at $60^{\circ}$ throughout the day while the left and right side reflectors were adjusted every two hours. In the experiments fresh tomatoes with initial moisture content of $95 \%$ were used. The tomatoes were 
sliced about $1.5 \mathrm{~cm}$ thick and $1 \mathrm{~cm}$ wide. Two set of tests were carried out with $5 \mathrm{~kg}$ and $10 \mathrm{~kg}$ of sliced tomatoes evenly distributed in the three trays. The photographic view of experimental setup is presented in figure 1 .

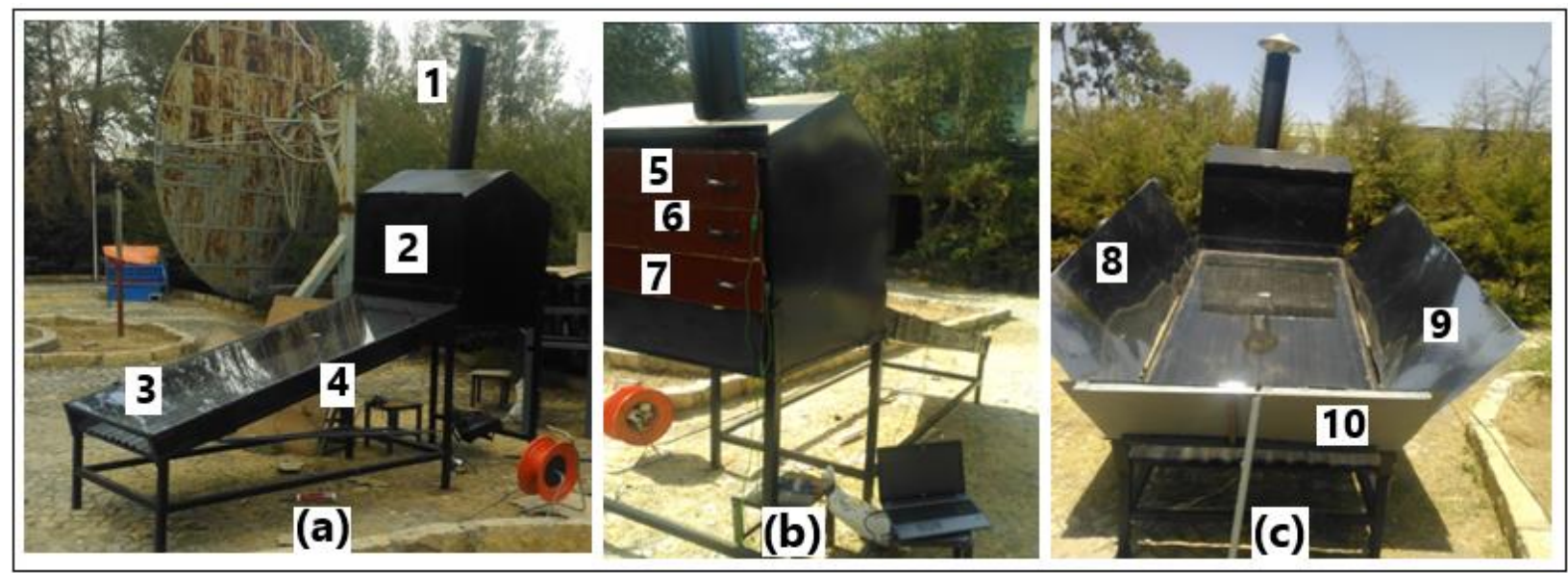

Figure 1. Pictorial view of dryer setup (a) without reflectors, (b) arrangement of trays, and (c) with reflectors (Note: 1. Chimney, 2. Drying cabinet, 3. Cover glass, 4. Collector, 5. Tray 1, 6. Tray 2, 7. Tray 3, 8. Right side reflector, 9. Left side reflector, 10. Bottom reflector).

The Estimation of the solar radiation incident on the collector surface was calculated using equation 9.The total solar radiation absorbed by the flat plate solar dryer collector is equal to the sum of direct radiation on the surface of collector $\mathrm{I}_{\mathrm{b}}$, the diffuse radiation by sky $\mathrm{I}_{\mathrm{ds}}$, the radiation reflected from the ground Is. The radiation reflected by the side reflector I 1 r left towards the collector with an inclined angle $\gamma_{1}$ and, the radiation reflected by the reflector on the right side toward the collector $I_{\mathrm{rr}}$ with tilted angle $\gamma_{2}$ and bottom reflector Ibo with tilted angle $\theta_{\mathrm{m}}$ is given as Tabet et al. (2017).

$I_{T}=I_{b}+I_{d s}+I_{s}+I_{1 r}+I_{r r}+I_{b o}$

The data collection and performance analysis of the dryer were carried out from March to May 2018 at Solar Demonstration Center, Mekelle University (latitude $13.4799^{\circ} \mathrm{N}$ and longitude $\left.39.4849^{\circ} \mathrm{E}\right)$. During this period there was very good solar radiation with mostly clear sky condition.

The thermal efficiency of the collector is defined as the ratio of heat output to the heat input or ratio of energy output to energy input, which is the same as the ratio of the energy addition to the air as it passes through the collector to the energy incident on the collector (Struckmann, 2008). 


$$
\text { Collector efficiency, } \eta_{c}=\frac{Q_{g}}{I_{T} A_{c}}=\frac{\dot{\mathrm{m}} \mathrm{C}_{\mathrm{p}}}{A_{c} I_{T}}
$$

Where, $\dot{\mathrm{m}}$ is mass flow rate of air, $\mathrm{kg} / \mathrm{s}, I_{T}$ is insolation on collector surface, $\mathrm{W} / \mathrm{m}^{2}$

$\Delta \mathrm{T}$ is change in temperature; ${ }^{\circ} \mathrm{C}$,

$\mathrm{C}_{\mathrm{p}}$ is air specific heat capacity, $\mathrm{J} / \mathrm{kg}{ }^{\circ} \mathrm{C}$

$\mathrm{Q}_{\mathrm{g}}$ is the useful energy gained,

$A_{c}$ is collector area, $\mathrm{m}^{2}$

$I_{T}$ is the total solar radiation

(but, for the case of reflectors it is global solar radiation plus reflected radiation from reflector).

The equation below is used to calculate the amount of moisture to be removed from the product, $\mathrm{m}_{\mathrm{w}}$, in $\mathrm{kg}$ (Dhanushkodi et al., 2014).

$$
m_{w}=\frac{m_{i}\left(M_{i}-M_{f}\right)}{100-M_{f}}
$$

Where, $m_{i}=$ initial mass of the food item $(\mathrm{kg})$;

$M_{i}=$ initial moisture content (\% dry basis);

$M_{f}=$ Final moisture content (\% dry basis);

Drying rate is the amount of evaporated moisture content over time. To calculate the drying rate the following formula is used (Dhanushkodi et al., 2014).

$\mathrm{DR}=\frac{M_{i}-M_{d}}{\mathrm{t}}$

Where,

$M_{i}$ is mass of sample before drying, in $\mathrm{kg}$,

$t$ is drying period, in hrs

$M_{d}$ is mass of sample after drying, in $\mathrm{kg}$.

The parameters measured during the evaluation of the solar dryer included temperature, mass of tomatoes at each tray, solar radiation and moisture content of the tomatoes at the beginning and end of the tests. The temperature inside the dryer cabinet and collector as well as the ambient temperature were measured by k-type thermocouples. The accuracy of the k-type thermocouple is $\pm 2.2^{\circ} \mathrm{C}$ or $\pm 0.75 \%$.

The K type thermocouple is connected with Pico Log TC-08 data logger to measure the dry bulb temperature at different locations of the solar collector and drying cabinet during 
experiment. A pyranometer of the type METEON irradiation meter was used to measure the global solar radiation. The pyranometer measures the sum of the beam and diffused solar radiation. The total solar radiation in $\mathrm{W} / \mathrm{m}^{2}$ was record by the data logger.

A moisture balance instrument model HB43-S (Mettler Toledo) was used to determine the amount of moisture content in the tomatoes before and after drying. A digital weighing scale model PT-600 was used to weigh the drying tomatoes to determine the weight loss. The initial weight of the tomatoes to be dried was weighed before placing in the dryer. Once the drying started, the tomatoes being dried were taken out from the dryer every two hours for the weight to be measured.

\section{RESULTS AND DISCUSSION}

\subsection{No Load Test}

No load tests were carried out in different days where the dryer was set with reflectors (WR) and with no reflectors (NoR). The tests were repeated for three days with each set up to know the variation of temperature at the collector and drying cabinet. Figure 2 shows representative data plot of both type of tests with reflector (WR) and with no reflector (NoR). The solar radiation measured for both days is included in the plot. Similar and very good radiation intensity was observed for both days.

It was observed that during the no reflector test the maximum absorber temperature reached was $98^{\circ} \mathrm{C}$ and the maximum temperature reached at the tray 2 was $48^{\circ} \mathrm{C}$. On the other hand during the test with reflectors the absorber temperature reached $154^{\circ} \mathrm{C}$ and the tray 2 temperature reached $61^{\circ} \mathrm{C}$.

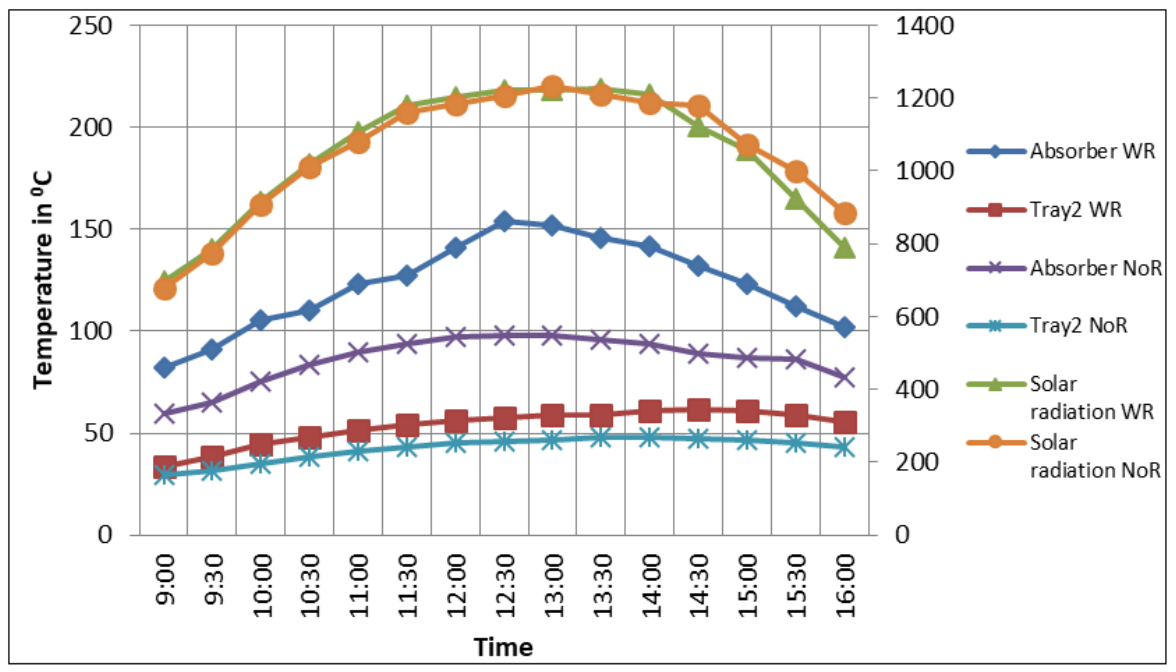

Figure 2. No load test result showing temperature variation with time of the day. 


\subsection{Drying Test without Reflectors}

Figure 3 shows a typical day results of the hourly variation of the temperatures in the solar collector and the drying cabinet during $5 \mathrm{~kg}$ load drying without reflectors.

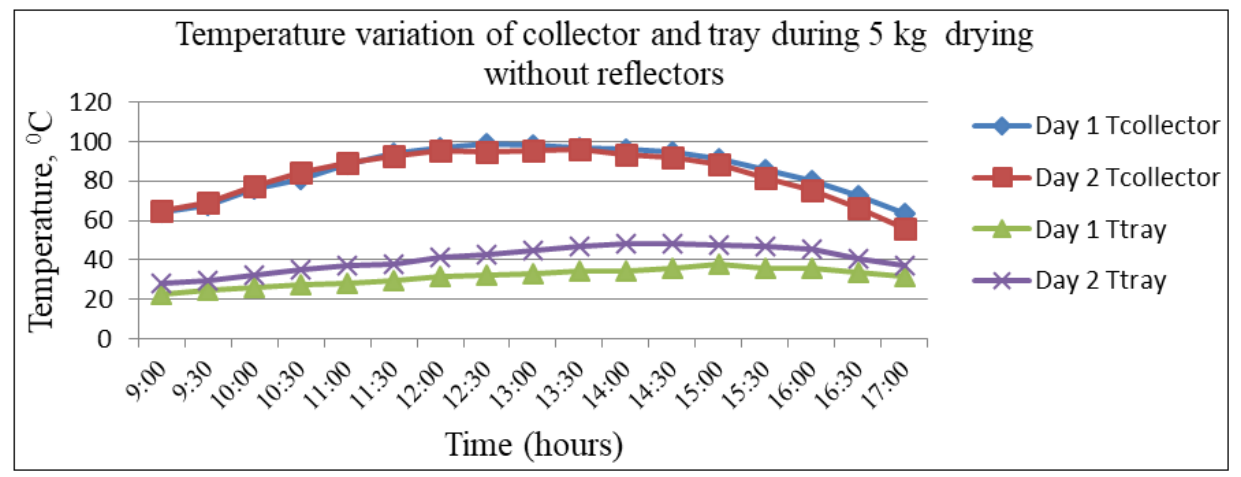

Figure 3.Temperature variation with time, $5 \mathrm{~kg}$ loadwithout reflectors.

From the graph it can be observed that the maximum collector temperature reached in the mid-day for day 1 and day 2 were $99^{\circ} \mathrm{C}$ and $95^{\circ} \mathrm{C}$ respectively. Average daily temperature inside cabin was around $34^{\circ} \mathrm{C}$ and $38^{\circ} \mathrm{C}$ whereas maximum temperature inside the cabinet for two days was up to $37.7^{\circ} \mathrm{C}$ and $48.4^{\circ} \mathrm{C}$. The observed rate of evaporation was higher in the first day compared with second day due to presence of high inherent moisture content.

Figure 4 shows a typical day results of the hourly variation of the temperatures in the solar collector and the drying cabinet during $10 \mathrm{~kg}$ load drying without reflectors.

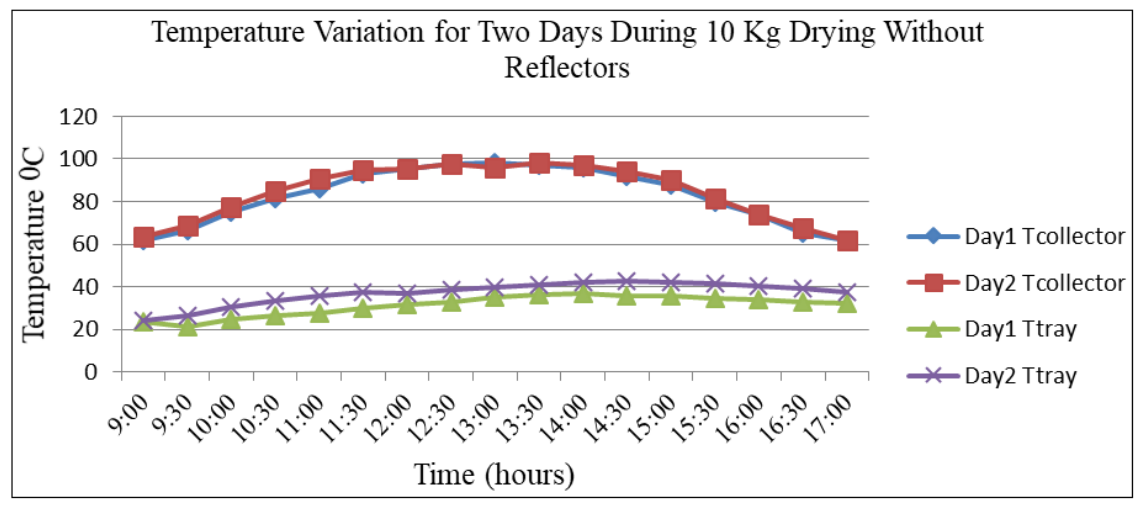

Figure 4.Temperature variation with time $10 \mathrm{~kg}$ without reflectors.

From the graph, it can be observed that the daily average temperature for the two days experiment in the drying unit was $32.3^{\circ} \mathrm{C}$ and $37.8^{\circ} \mathrm{C}$ respectively with loading of $10 \mathrm{~kg}$ sliced tomatoes. The maximum temperature reached during the two days test was around $97^{\circ} \mathrm{C}$, while the 
temperatures at the tray were $36^{\circ} \mathrm{C}$, and $42.5^{\circ} \mathrm{C}$ for day 1 and day 2, respectively. Maximum temperature reached in the cabinet was less during the first day due to high moisture content in the tomato slices.

\subsection{Drying Test with Reflectors}

Figure 5 shows a typical day results of the hourly variation of the temperatures in the solar collector and the drying cabinet with reflectors during $5 \mathrm{~kg}$ sliced tomato drying. It can be noticed that the maximum collector temperature attained for the ensuing two days was $135.6^{\circ} \mathrm{C}$ and $127.5^{\circ} \mathrm{C}$. For day 1 and day 2 the average daily temperature inside cabinetwas around $41.0^{\circ} \mathrm{C}$ and $53.8^{\circ} \mathrm{C}$ and the maximum temperature inside the cabinet was up to $49.7^{\circ} \mathrm{C}$ and $62.3^{\circ} \mathrm{C}$ respectively. The temperatures at the absorber during the test days were found to be higher than the tests during the no reflector cases by around $40^{\circ} \mathrm{C}$. This result is similar to the no load tests carried out for both no reflector and with reflector cases.

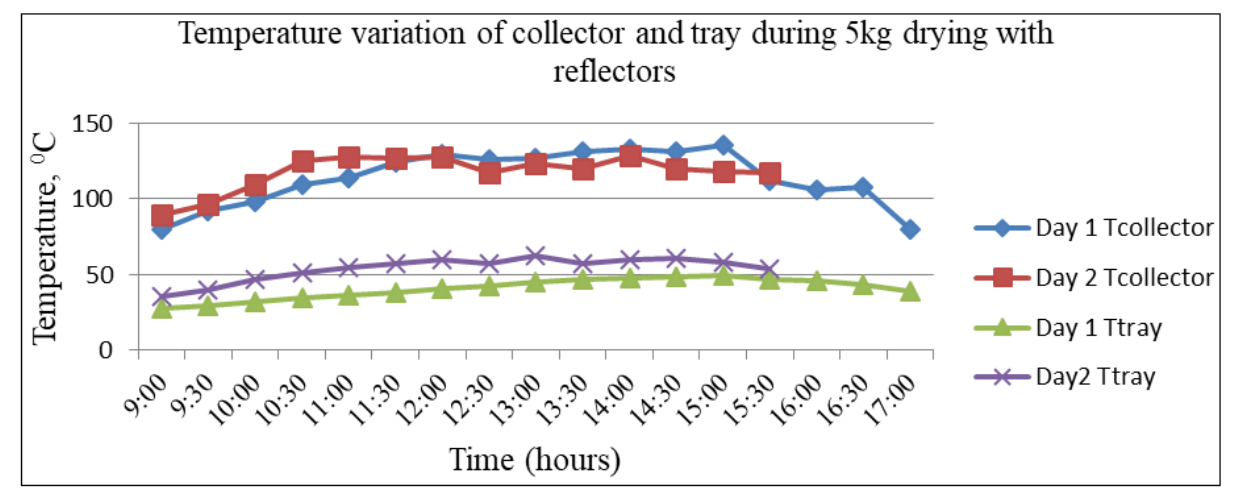

Figure 5. Temperature variation with time, $5 \mathrm{kgwith}$ reflectors.

Figure 6 shows a typical day results of the hourly variation of the temperatures in the solar collector and the drying cabinet with reflectors during $10 \mathrm{~kg}$ sliced tomato drying.

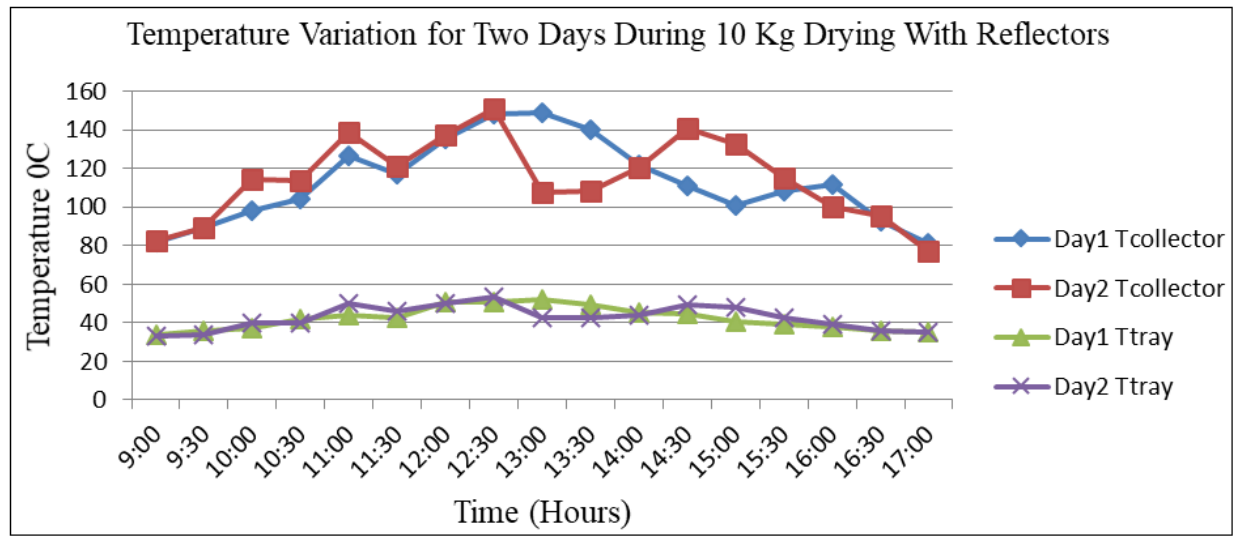

Figure 6.Temperature variation with time, $10 \mathrm{~kg}$ with reflectors. 
During two days experiment 10kg drying of the solar dryer with reflectors, the daily average temperature in the drying unit was $43.2^{\circ} \mathrm{C}$ and $42.8^{\circ} \mathrm{C}$ respectively. The maximum temperature reached of the collector and cabinet was $149^{\circ} \mathrm{C}, 52^{\circ} \mathrm{C}$ and $150^{\circ} \mathrm{C}, 53^{\circ} \mathrm{C}$ respectively. The maximum temperature reached during the two days test was around $150^{\circ} \mathrm{C}$, while, the temperatures at the tray were around $52^{\circ} \mathrm{C}$. It is important to note that in this test on the second day in the period between 13:00 to 14:00 there was problem in the adjustment of the reflectors and hence significant temperature drop was observed.

\subsection{Weight Loss Calculations for the Tests without and with Reflectors}

To estimate the weight loss, the tomato slices were weighed every two hours using the digital weighing scale and the results are shown in figure 7.

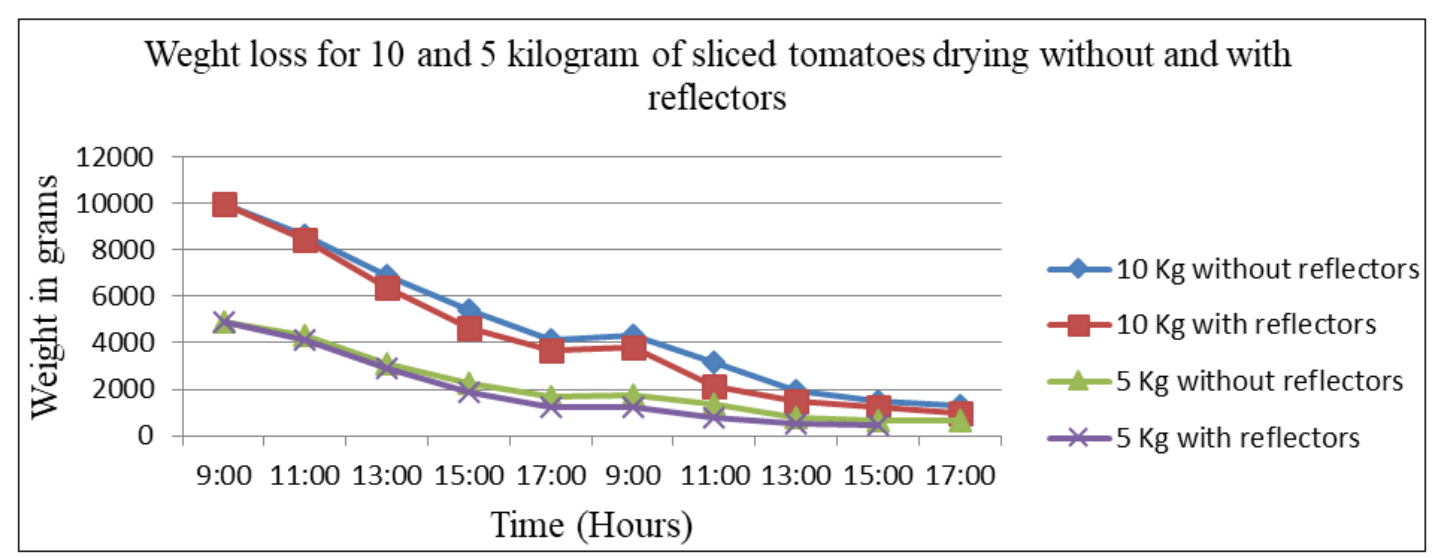

Figure 7.Weight loss of tomato slices for day 1 and 2, with and without reflectors for 10 and $5 \mathrm{~kg}$ load.

The weight loss during the first day for the $5 \mathrm{~kg}$ without reflectors experiment was $65.6 \%$, whereas for the second day it was $37.1 \%$. The reduction in the weight loss for the two days was found to be $87.2 \%$. After two days of drying the moisture content reached $12.8 \%$ still above the $10 \%$ requirement. On the other hand, the weight loss during $5 \mathrm{~kg}$ with reflectors experiments was $74.7 \%$ and $35.9 \%$ for day 1 and day 2, respectively. The reduction in the weight loss for two days was found to be $91 \%$.In the second day the final required moisture content was attained at 15:00.

Similarly, the drying test for the case of $10 \mathrm{~kg}$ tomato without reflectors indicates that the weight loss was $58.5 \%$ after one day and reached $88.5 \%$ at the end of two days. The moisture content was above $10 \%$ after two days of drying. For the case with reflectors the weight loss was $63.4 \%$ on the first day and $91.5 \%$ at the end of the second day. The required moisture content was attained at the end of two days of drying. 
During the experiment, it can be observed that there was increment of weight of the tomatoes at the beginning of the second day compared to the weight at the end of the first day. This is due to moisture re-absorption by the tomatoes during the night.

Figure 8 depicts drying rate for 5 and $10 \mathrm{~kg}$ tomato slices with respect to time of the solar dryer without and with reflectors.

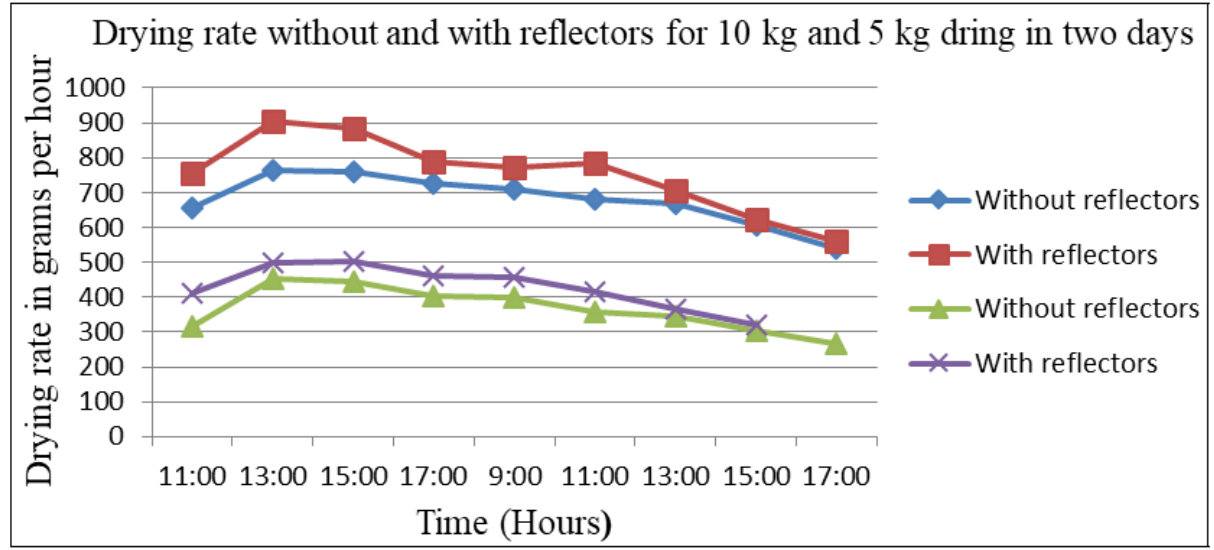

Figure 8. Drying rate of the solar dryer without and with reflectors during the two days drying.

From the graph it was observed that the drying rate for both cases reached the maximum on the first around noon time. The drying rate then decreased beyond noon time and during the second day as well. In the second day, as more moisture is extracted from the tomato, it becomes more difficult to extract further. The daily average drying rate for $5 \mathrm{~kg}$ load without and with reflectorswas $403.5 \mathrm{~g} / \mathrm{h}$ and $459.6 \mathrm{~g} / \mathrm{h}$, respectively. While for the $10 \mathrm{~kg}$ load the dry rate was found to be $727.8 \mathrm{~g} / \mathrm{h}$ and $789 \mathrm{~g} / \mathrm{h}$, respectively. Therefore, there was increase in performance of the dryer due to the addition of reflectors by about $8 \%$ for the $10 \mathrm{~kg}$ load and about $14 \%$ for the 5 $\mathrm{kg}$ load.

\section{CONCLUSION}

Experimental investigation on a solar dryer to improve its performance by adding reflectors was carried out. No load and drying tests were conducted for both without reflector and with reflector cases. During no load test the average maximum collector temperature at the absorber plate without and with reflectors was found to be $98^{\circ} \mathrm{C}$ and $154^{\circ} \mathrm{C}$, respectively. This indicated a significant improvement on the solar dryer due to the addition of reflectors. 
During drying experiments with tomato slices, maximum temperatures reached at the absorber plate and inside the cabinet were around $100^{\circ} \mathrm{C}$ and around $48^{\circ} \mathrm{C}$ for the dryer without reflector. On the other hand, maximum temperatures reached at the absorber plate and inside the cabinet were around $150^{\circ} \mathrm{C}$ and around $62^{\circ} \mathrm{C}$ for the dryer without reflector. Due to the improvement on the temperature of the collector, the drying performance was increased by $8 \%$ for the $10 \mathrm{~kg}$ load and by $14 \%$ for the $5 \mathrm{~kg}$ load case.

\section{ACKNOWLEDGEMENTS}

The authors acknowledge the support from Capacity 5 project coordinated by EiT-M, Mekelle University, a collaborative project of the EnPe program of the Norwegian Government.

\section{CONFLICTS OF INTERESTS}

The authors declare no conflict of interest.

\section{REFERENCE}

Dawit Abay Tesfamariam. 2013. Design and Development of Solar Dryer for Rural Application. M.Sc thesis, Department of Mechanical Engineering, Mekelle University.

Dawit Abay Tesfamariam, Mulu Bayray, Meseret Tesfay \& Ftwi Yohaness Hagos. 2015. Modeling and Experiment of Solar Crop Dryer for Rural Application. Journal of Chemical and Pharmaceutical Sciences (Special Issue, 9): 109-118.

Dhanushkodi, S., Wilson, V. H \& Sudhakar, K. 2014. Thermal Performance Evaluation of Indirect Forced Cabinet Solar Dryer for Cashew Drying. American-Eurasian Journal Agriculture. \& Environmental Science, 14(11): 1248-1254.

Dikbasan, T. 2007. Determination of Effective Parameters for Drying of Apples. MSc thesis, İzmir Institute of Technology, Energy Engineering, İzmir Turkey, 78p (http://hdl.handle.net/11147/3917).

Hailay Teklu. 2018. Performance Enhancement of Natural Convection Solar Dryer Integrated with Reflectors for Drying Fruits and Vegetables. M.Sc thesis, School of Mechanical and Industrial Engineering, Mekelle University.

Hawlader, M.N.A., Pera, C.O \& Tian, M. 2005. Influence of Different Drying Methods on Fruits' Quality. In $8^{\text {th }}$ Annual IEA Heat Pump Conference, Las Vegas, USA, 150p. 
Hawlader, M.N.A., Pera, C.O \& Tian, M. 2006. Comparison of the Retention of 6- Gingerol in Drying of Ginger under Modified Atmosphere Heat Pump Drying and other Drying Methods. Drying Technology, 24: 51-56.

Hermann, S. 2004. The Solar Economy: Renewable Energy for a Sustainable Global Future. Earthscan Publications Ltd, London, ISBN 1-84407-075-I, 347p.

Raju, R. V. S., Reddy, R. M \& Reddy, E. S. 2013. Design and Fabrication of Efficient Solar Dryer. Journal of Engineering Research and Applications, 3(6): 1445-1458.

Seveda, M. S. 2013. Design of a Photovoltaic Powered Forced Convection Solar Dryer in NEH Region of India. International Journal of Renewable Energy Research, 3(4): 1-7.

Struckmann, F. 2008. Analysis of a Flat-plate Solar Collector. Project Report: 2008 MVK 160 Heat and Mass Transport. Lund University, Lund, Sweden, $4 \mathrm{p}$.

Tabet, I., Touafek, K., Bellel, N., Khelifa, A \& Baissi, M.T. 2017. Thermal Performance of Flat Plate Solar Collector with Reflectors in South Algeria. Journal of Sustainable Energy, 8(2): 47-53. 